\title{
DINÂMICA DISCURSIVA E O ENSINO DE FÍSICA: ANÁLISE DE UM EPISÓDIO DE ENSINO ENVOLVENDO O USO DE UM TEXTO ALTERNATIVO
}

\author{
Discursive dynamic and the physics teaching: analysis of a teaching episode \\ concerning an alternative text use
}

\author{
Alice Assis ${ }^{1}$ \\ Odete Pacubi Baierl Teixeira ${ }^{2}$
}

\begin{abstract}
Resumo
Este artigo enfoca a análise da dinâmica discursiva entre alunos e professor mediados pelo uso de um texto alternativo intitulado "Nosso Universo", em aulas de Física, em uma sala de educação de jovens e adultos. Para tal, é destacado um episódio de ensino cuja abordagem centra-se na discussão de conceitos físicos. Os resultados evidenciaram que o referido texto mostrou-se potencialmente significativo para os alunos, aguçando a curiosidade e o interesse dos mesmos, que relacionaram os conteúdos abordados com os seus conhecimentos prévios. Esse fator vinculado ao papel mediador do professor, que assumiu uma postura dialógica, resultou na facilitação da aprendizagem significativa crítica por parte dos estudantes.
\end{abstract}

Palavras-chave: Ensino de Física; leitura; argumentação.

\begin{abstract}
This paper focuses the discursive dynamic analysis among pupils and teacher using an alternative text called "Our Universe", in physics classes for young and adult people. A teaching episode about physics concepts discussion was used and the results showed that this text was potentially significant to pupils, who had their curiosity and interest increased, besides of their relating of discussed topics with previous knowledge. This fact associated to the teacher's interceding role, who assumed a dialogical approach, resulted in an easier students' significant critical leaning.
\end{abstract}

Keywords: Physics teaching; reading; discourse.

${ }^{1}$ Faculdade de Engenharia de Guaratinguetá - UNESP - Guaratinguetá - SP alice@feg.unesp.br

${ }^{2}$ Faculdade de Engenharia de Guaratinguetá - UNESP - Guaratinguetá - SP. opbt@feg.unesp.br 


\section{Introdução}

O ensino de Física, muito freqüentemente, é caracterizado por resoluções automáticas de equações desprovidas de significado para o estudante, ficando a explicação conceitual relegada a um segundo plano, o que dificulta o entendimento de seus fenômenos e conceitos.

Desse modo, considera-se que a utilização de textos alternativos, em aulas de Física, pode se instituir como uma ferramenta didática capaz de promover a compreensão do aluno acerca dos conceitos apresentados, possibilitando contextos de aprendizagem e mediando a interação entre professor e alunos de modo a viabilizar a produção de múltiplos sentidos e a capacidade de argumentação por parte dos estudantes.

Neste artigo analisamos um recorte de um episódio de ensino relativo a um trabalho de pesquisa (ASSIS, 2005), cujo objetivo foi o de analisar os resultados da utilização de um texto paradidático, intitulado "Nosso Universo", como recurso didático-pedagógico em aulas de Física, em uma sala de educação de jovens e adultos. A análise dessa pesquisa centrou-se no tripé professor-aluno-texto, enfocando como o professor e os alunos, mediados pelo recurso envolvendo o referido texto, utilizaram o discurso para estruturar as suas idéias.

\section{Pressupostos teóricos}

Segundo os Parâmetros Curriculares Nacionais para o Ensino Médio (BRASIL, 2002) a Física deve ser apresentada aos alunos, de modo a viabilizar que os mesmos possam, a partir dos seus princípios, leis e modelos, "perceber e lidar com os fenômenos naturais e tecnológicos, presentes tanto no cotidiano mais imediato quanto na compreensão do universo distante" (p.59). Constituintes desse contexto encontramse as terminologias e os conceitos próprios da Física, bem como as suas formas de expressão, tais como tabelas, gráficos e relações matemáticas.

Nesse sentido, é necessário que os conhecimentos relativos à física sejam tratados e entendidos como instrumentos para a compreensão do mundo, de forma que os seus conteúdos possam ser trabalhados de modo a enfocar os seus significados no sentido de transcender a sua dimensão pragmática, com o objetivo de preparar o estudante para lidar com as situações que vivencia ou mesmo que possa vir a vivenciar 
(BRASIL, 2000). Esse enfoque, inserido em um contexto mais amplo, pode viabilizar a formação do aluno enquanto indivíduo crítico e reflexivo.

Para tal, se faz necessário trabalhar informações atualizadas sobre ciência e tecnologia, a fim de tornar os conteúdos mais significativos para os estudantes. Desse modo, consideramos que o uso de textos alternativos, com abordagens contextualizadas, pode recuperar na escola e particularmente nas aulas de física o interesse por parte dos alunos em conhecer, bem como, produzir contextos de aprendizagem.

No entanto, Almeida e Queiroz (1997) destacam que para que a utilização desses textos leve à compreensão dos conceitos e à satisfação em ler, é necessário que sejam criadas "condições de leitura que modifiquem as práticas escolares usuais" (p.65), superando-se as práticas que restrinjam a leitura a uma "interpretação imediata e única". A não superação dessas práticas implica na criação de barreiras na interação entre o aluno e o texto, levando-o à não compreensão dos conceitos e sim à memorização dos mesmos. Desse modo, considera-se que a utilização de textos como ferramenta didática, com o propósito de viabilizar a superação das referidas práticas, requer uma abordagem dialógica.

Além disso, é imprescindível a mediação do professor, introduzindo novas idéias, para levar o aluno à compreensão dos conceitos trabalhados no texto. Assim, o desenvolvimento do conteúdo do discurso se dá na medida em que as abordagens comunicativas vão sendo produzidas por meio de diferentes padrões de interação e intervenção do professor (MORTIMER e SCOTT, 2002, p.33 e 35). As classes de abordagens comunicativas utilizadas para estruturar a análise da dinâmica discursiva desta pesquisa foram as seguintes: - Interativa/dialógica: professor e estudantes exploram idéias, formulam perguntas autênticas e oferecem, consideram e trabalham diferentes pontos de vista; - Não-interativa/dialógica: professor reconsidera, na sua fala, vários pontos de vista, destacando similaridades e diferenças; - Interativa/de autoridade: professor geralmente conduz os estudantes por meio de uma seqüência de perguntas e respostas, com o objetivo de chegar a um ponto de vista específico; - Nãointerativa/de autoridade: professor apresenta um ponto de vista específico.

Utilizamos ainda os padrões discursivos lúdico, polêmico e autoritário, destacados por Orlandi (2001). No discurso lúdico os alunos são instigados a explicitarem as suas opiniões, por meio de uma polissemia aberta. No discurso polêmico, o professor direciona as respostas dos alunos, indicando perspectivas 
particularizadas, por meio de uma polissemia controlada, a fim de levar os estudantes a uma resposta determinada. No discurso autoritário não há interlocutores, uma vez que o professor não abre espaço para a fala do aluno, resultando assim em uma polissemia contida.

Por outro lado, em se tratando de uma aprendizagem que seja significativa e crítica, Moreira (2000) estabelece algumas condições necessárias para viabilizá-la, caracterizando um episódio de ensino. Dentre essas condições, destacamos que a interação social, mediante a negociação de significados por meio de uma troca constante de perguntas é imprescindível para a consumação de um episódio de ensino. Nesse processo, a conscientização de que a atribuição de significados é individual vincula-se ao fato de que cada aluno percebe e representa o mundo de acordo com a sua ideologia. Essa percepção por parte do aluno é importante no sentido de que o mesmo deixa de acreditar que existem respostas necessariamente certas ou erradas. Outra condição destacada pelo autor vincula-se à percepção de que a linguagem não é neutra, mas expressa e reflete o pensamento. Nesse contexto, aprender os conteúdos científicos de forma significativa implica em aprender a sua linguagem, o que decorre em aprender a falar e pensar de modo diferente acerca do mundo. Nesse sentido, considera-se que o papel do professor seja o de mostrar ao aluno as idéias científicas atualmente aceitas, discernindo-as das idéias do senso comum, bem como mostrar o caráter dinâmico e provisório dos conhecimentos científicos.

Com isso, Moreira (2000) destaca que a comunicação entre professor e alunos só é possível na medida em que os mesmos busquem perceber os materiais educativos do currículo de forma semelhante, o que fortalece "a importância da interação pessoal e do questionamento na facilitação da aprendizagem significativa". Segundo Gowin (apud MOREIRA, 2003, p.7), há uma "relação triádica entre professor, materiais educativos e aprendiz", de modo que um episódio de aprendizagem caracteriza-se pelo "compartilhar significados entre aluno e professor" acerca dos conhecimentos veiculados pelos referidos materiais, ocorrendo uma busca de "congruência de significados" pelos mesmos. Para Moreira (2000), a busca de materiais alternativos para trabalhar os conteúdos é necessária para que os alunos superem a visão do livro didático como armazenador de todo o conhecimento.

No entanto, para que ocorra a facilitação da aprendizagem significativa crítica em sala de aula, além do papel mediador do professor, também são relevantes outros dois aspectos: que o material de aprendizagem seja "potencialmente significativo", ou 
seja, relacione-se com a estrutura cognitiva do aprendiz de maneira não arbitrária e substantiva (não literal); que o aprendiz manifeste disposição em aprender, ou seja, em "relacionar de maneira substantiva e não arbitrária o novo material, potencialmente significativo, a sua estrutura cognitiva" (AUSUBEL, apud MOREIRA, 1995, p.66)

Mediante esses pressupostos teóricos, estruturamos a análise da dinâmica discursiva do presente artigo, a fim de verificarmos se o discurso do professor mediando a interação entre os alunos e o texto "Nosso Universo", levou os estudantes a demonstrarem, por meio de seus argumentos, se o referido contexto promoveu a facilitação da aprendizagem significativa crítica acerca dos conhecimentos trabalhados.

\section{O texto}

O texto intitulado "Nosso Universo" (TEIXEIRA, 2002) foi elaborado por seis professores de Física do Ensino Médio, sob a coordenação de um docente do curso de licenciatura em Física da Unesp de Guaratinguetá, enquanto participantes de um programa de formação continuada, inserido no Programa de Pesquisa Aplicada para a Melhoria do Ensino Público no Estado de São Paulo (Fapesp), denominado “A Leitura como Veículo Promotor da Aprendizagem em Conteúdos de Física”. O texto é constituído por cinco capítulos, apresentando um apêndice ao final de cada um deles, em que constam informações adicionais acerca de alguns conceitos abordados, bem como sugestões de pesquisas em sites, filmes e leituras de livros. No decorrer dos capítulos, os conteúdos científicos são trabalhados por meio de algumas situações vivenciadas pelo adolescente Ícaro, de modo a despertar o interesse e a curiosidade do leitor.

O texto articula os conhecimentos científicos com o cotidiano, abordando vários conteúdos relacionados à Física de forma desfragmentada e não linear. Trabalha conteúdos de várias disciplinas e utiliza a história da ciência para mostrar o caráter dinâmico dos conhecimentos científicos.

A partir dessas características, supõe-se, a priori que, se o referido texto for trabalhado de acordo com uma perspectiva dialógica, pode-se recuperar na escola e particularmente nas aulas de física o interesse por parte dos alunos em conhecer, bem como, produzir contextos de aprendizagem. 


\section{Objetivo}

O presente artigo visa analisar, por meio dos argumentos dos alunos e do professor, se a relação triádica professor/alunos/texto favoreceu a construção de um espaço dialógico em sala de aula de modo a contribuir para a ocorrência de aprendizagem significativa crítica por parte dos estudantes, acerca dos conceitos abordados.

\section{Metodologia}

Realizada dentro de uma abordagem qualitativa, a presente atividade de pesquisa foi realizada no primeiro semestre do ano letivo de 2004, tendo como sujeitos constituintes da pesquisa 14 alunos da $3^{\mathrm{a}}$ série do ensino de jovens e adultos (supletivo), do período noturno, na faixa etária de 18 a 45 anos, de uma escola estadual situada no Centro Oeste paulista, bem como o professor de Física da referida sala.

Cada capítulo foi apresentado aos alunos no momento da aula. A leitura dos mesmos foi feita por vários alunos, em voz alta. Deixou-se claro que essa leitura poderia ser interrompida em qualquer instante, para qualquer comentário ou pergunta que o aluno desejasse formular. Procurou-se, ainda, deixar os alunos à vontade para que pudessem se expor sem medo de "errar".

Todas as aulas foram vídeo gravadas e ao final de cada capítulo os alunos realizaram uma avaliação sobre os mesmos. O processo avaliativo se deu continuamente, levando-se em consideração a participação dos alunos e o nível de interesse dos mesmos, bem como o processo interativo no decorrer da atividade. De modo geral, pode-se dizer que as avaliações corresponderam a um momento privilegiado de estudo, em que os alunos explicitaram as suas opiniões sem constrangimentos.

Para a elaboração do presente artigo foi analisada a transcrição relativa ao episódio 5 do Capítulo II, cuja leitura propiciou que fossem trabalhados os conceitos de massa, peso, campo gravitacional e velocidade de escape.

\section{As categorias utilizadas como instrumentos para a análise dos dados}

As seguintes categorias de análise das argumentações discentes foram elaboradas por Assis (2005), a partir de uma leitura prévia das transcrições das 
vídeogravações, considerando-se a postura dos alunos no que se refere aos tipos de argumentos utilizados por eles:

Ação Argumentativa Elaborativa (AAE): identifica se um determinado aluno durante o contexto de discussão de um determinado problema ou fenômeno elabora uma explicação para esse fenômeno ou problema.

Ação Argumentativa Concordante (AAC): identifica se um determinado aluno durante o contexto de discussão de um determinado problema ou fenômeno concorda com a explicação elaborada por outro aluno ou pelo professor para esse fenômeno ou problema.

Ação Argumentativa Questionadora (AAQ): identifica se um determinado aluno durante o contexto de discussão de um determinado problema ou fenômeno questiona ou discorda de uma explicação apresentada por outro aluno, pelo professor, pelo texto para esse fenômeno ou problema, ou mesmo coloca alguma dúvida para ser esclarecida.

Ação Argumentativa Reelaborativa (AAR): identifica se um determinado aluno durante o contexto de discussão de um determinado problema ou fenômeno reelabora explicações anteriormente apresentadas para esse fenômeno ou problema.

Ação Argumentativa Investigativa (AAInv): identifica se o aluno busca o esclarecimento das dúvidas no texto, ou até se o mesmo fundamenta-se no texto para levantar questões.

Ação Argumentativa de Inserção (AAIns): identifica se o aluno insere algum elemento novo à discussão.

Para caracterizar o discurso do professor em sala de aula foram utilizadas as categorias retórica, socrática e dialógica, propostas por Boulter e Gilbert (1995) e as subcategorias organizadas por Monteiro (2002), inspirado nas categorizações elaboradas por Compiani (1996):

Argumentação Retórica:

- de Contextualização (ARC): professor promove o envolvimento dos alunos com o tema em questão, utilizando-se de sua autoridade para determinar os objetivos e conteúdos a serem considerados. Embora as idéias dos alunos não sejam levadas em consideração, desempenhando um papel passivo, essa postura do professor mostra a sua preocupação com a aprendizagem dos conceitos ensinados.

- de Exposição (ARE): transmissão de informações que podem subsidiar a compreensão dos alunos do assunto em questão. O processo discursivo não é 
desencadeado por questões propostas aos alunos, mas sim organizado pelo professor. Aqui também o aluno desempenha um papel passivo.

Argumentação Socrática:

- de Fornecimento de Pistas (ASFP): professor dirige o raciocínio dos alunos, o que se dá por meio de uma explicação, ou do fornecimento de elementos que sustentem uma linha de raciocínio que levem o aluno à resposta correta, ou mesmo por meio de uma série de questões que conduzam o aluno a determinadas conclusões.

- de Remodelamento (ASRem): professor destaca algumas idéias colocadas pelos alunos que necessitam de maior detalhamento e precisão. Correspondem a ajustes realizados pelo professor, preenchendo lacunas conceituais, dando contornos precisos a determinados conceitos, a partir das idéias construídas pelos alunos.

- de Reespelhamento (ASRee): professor autoriza ou não as idéias dos alunos. Usando de sua autoridade discursiva, ao repetir com ênfase ou gesticular de modo favorável, o professor legitima a idéia do aluno, o que inibi outras idéias contrárias. No entanto, por meio de uma negativa, ou mesmo da espera por outras respostas, o professor está indicando ao aluno que as suas idéias não estão corretas.

- de Elucidação (ASE): fala do professor que se dá a partir de perguntas colocadas pelos alunos, com o objetivo de clarear algumas idéias já expostas, mas não compreendidas pelos alunos.

\section{Argumentação Dialógica:}

- de Instigação (ADI): professor incentiva os alunos a explicitarem as suas opiniões, bem como a iniciarem o processo de interação em sala de aula.

- de Contraposição (ADC): professor destaca pontos contraditórios nos argumentos dos alunos ou busca gerar conflitos a fim de desencadear o confronto entre as idéias expostas.

- de Organização (ADO): professor busca a sistematização das idéias explicitadas pelos alunos, com o objetivo de "situá-los nas concordâncias e discordâncias", viabilizando novas interações em sala de aula. Esse momento propicia a articulação entre as idéias colocadas.

- de Recapitulação (ADRecap): professor sintetiza todas as idéias discutidas pelos alunos para finalizar o debate.

- de Recondução (ADRecon): professor retoma o "desenvolvimento de pertinência das discussões" estabelecidas em sala de aula. "O professor regula a 
discussão definindo os limites e as derivações que não pertencem aos objetivos propostos pela aula."

- fala avaliativa (FA): professor busca a lógica usada pelos alunos em determinadas afirmações. Esse procedimento investiga os motivos pelos quais os alunos externam uma opinião

\section{Análise dos dados}

A seguir, destacamos o Episódio 5, analisado no presente artigo, em que Ícaro discute com o seu amigo Dédalo o conceito de força de atração gravitacional. Esse conceito surgiu neste episódio, em virtude de os episódios anteriores abordarem o modelo que explica a formação do universo. Ressaltamos que denominamos de episódio cada trecho lido até a ocorrência de uma interrupção, seja por parte de algum aluno ou do professor.

\section{Episódio 5 - Capítulo II}

Ícaro: Nossa! É mesmo! Eu já tava fazendo confusão, peso é diferente de massa, peso é força. Mas como vc achou esse valor? Isso é muito ou pouco?

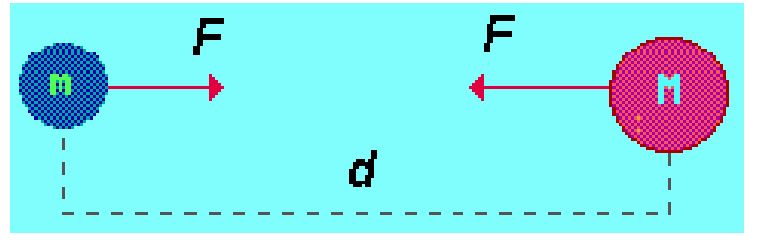

Dédalo: Lembra do Newton? De um dos seus trabalhos resultou uma elegante Lei que relaciona a força com a massa e a distância entre corpos. Matematicamente, essa lei pode ser expressa através da equação: $F=\frac{G \cdot M \cdot m}{d^{2}}$, onde $G=6,67 \cdot 10^{-11} \frac{\mathrm{N} \cdot \mathrm{m}^{2}}{\mathrm{~kg}^{2}}$ é uma constante, válida para qualquer lugar do universo e, por isso, recebe o nome de "constante universal da gravitação". Então é só substituir os dados na expressão matemática que você encontrará esse valor. Você disse que peso é força e isso é verdade, pois peso nada mais é do que a força com que a Terra, por ter massa, atrai os corpos que também têm massa.

Ícaro: Mas, afinal de contas, esse valor que vc achou é muito ou pouco?

Dédalo: Para entender melhor, se vc se lembrar que $\mathrm{P}=\mathrm{m} \cdot \mathrm{g}$, que sua massa é $70 \mathrm{~kg}$ e considerando $g=10 \frac{\mathrm{m}}{\mathrm{s}^{2}}$, fazendo o cálculo, verá que seu peso é de $700 \mathrm{~N}$ na superfície terrestre. Comparando com o valor da força de atração entre você e seu colega, que é de $3,27.10^{-7} \mathrm{~N}$, ou seja $0,000000327 \mathrm{~N}$ fica claro que esse valor passa despercebido no nosso dia-a-dia. 
Após a leitura desse episódio ocorreu o seguinte fluxo de comunicação.

Discussões relativas ao Episódio 5 - Capítulo II

154. P: Espera ai, vamos lá! Então veja bem, como é que se pode
calcular o peso, a força entre dois corpos, o peso é a força que o
planeta atrai os corpos. P=mg, uma pessoa de $70 \mathrm{~kg}$ o g é o valor
da gravidade vale aproximadamente $10 \mathrm{~m} / \mathrm{s}^{2}$. Então uma pessoa de
massa $70 \mathrm{~kg}$ o peso dela é: $70 \mathrm{~kg}$ vezes $10 \mathrm{~m} / \mathrm{s}^{2}$ que dá $700 \mathrm{~N}, 700 \mathrm{~N}$
é a força com que a Terra atrai uma pessoa de $70 \mathrm{~kg}$. Se for
calcular por aqui também a força com que a Terra atrai a pessoa
daria o mesmo valor, essas fórmulas, essas equações dizem a
mesma coisa, sabem por quê? Olha só: este G aqui ó, este G grande
não é igual a este g pequeno, que é o g da gravidade. Este G grande
é chamado constante de gravitação universal, uma constante que
vale para qualquer lugar do universo. Nós temos aqui a Terra
aproximadamente circular redonda, aqui está o centro da Terra,
aqui é a superfície da Terra a pessoa está aqui neste ponto, esse d
seria a distancia do centro da terra até onde a pessoa se encontra.
o g da gravidade ele é isto aqui ó, vocês viram? o g da gravidade é
(...) como nós podemos obter o g da gravidade? Fazendo G vezes a
massa da Terra dividido pelo raio da Terra ao quadrado, por isso
que essas fórmulas dizem a mesma coisa. Isto aqui é o g da
gravidade, esta conta da 10, se alguém quiser fazer depois, pegar o
valor da constante G, vezes a massa da Terra dividido pelo raio da
terra ao quadrado, vai obter aproximadamente 10, por isso que
essas fórmulas dizem a mesma coisa. Alguém quer dizer alguma
coisa sobre isso?
155 . Oli: No caso o kg é um peso estável, e já o kgf é uma força aplicada?

156. P: exatamente!

157. Oli: Aquela atração lá você quis dizer que tem uma força, mas só que aqui está constando $\mathrm{kg}$, se tem força tem que ter $\mathrm{kgf}$.

158. P: Veja bem, o kg mede a massa da pessoa.

159. Oli: Peso estável.

160. P: Você está chamando de "peso estável" o que seria massa?

161. Oli: Isso.

162. P: A massa da pessoa é igual na Terra, na Lua, em Marte, em Júpiter, a massa não muda. O que muda é o que?

163. Hel: O peso muda.

164. Wag: Porque a gravidade não é igual.

165. P: Exatamente! Porque o peso é a massa vezes a gravidade (g), se a gravidade do local for diferente, o peso dá diferente, a massa não, a massa fica sempre a mesma. A gravidade na Lua é seis vezes menor que na Terra, o peso de uma pessoa na Lua é seis vezes menor do que na Terra, só que a massa é a mesma, vamos lá.

166. Wag: Professor! Voltando um pouco sobre a gravidade, o que ocorre com o foguete se ele não atingir essa velocidade, ele cai?

167. P: Ele não sai da Terra.

168. Wag: Mas ele continua numa linha reta, ele não vai sair (...). Então vai chegar uma hora ele vai parar?
154. ARC

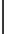

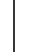

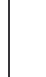

.

.

.




\begin{tabular}{|c|c|}
\hline $\begin{array}{l}\text { 169. P: Então onde que ele vai? Ele sai em linha reta? Qual é } \\
\text { trajetória que o foguete faz? }\end{array}$ & \\
\hline 170. Wag: Para cima, em linha reta para cima. & 170. AAE \\
\hline $\begin{array}{l}\text { 171. Mur: A Terra vai expulsar ele para baixo para ele mudar a } \\
\text { trajetória dele. }\end{array}$ & AAE, AAIns \\
\hline 172. P: Como é que é? & 172. FA \\
\hline $\begin{array}{l}\text { 173. Mur: Por cima da Terra, a gravidade da atmosfera vai } \\
\text { empurrar ele de volta para a Terra. }\end{array}$ & \\
\hline $\begin{array}{l}\text { 174. P: A gravidade da atmosfera? } \\
\text { 175. Mur: Ahn! }\end{array}$ & 174. ASRee \\
\hline $\begin{array}{l}\text { 176. P: O foguete vai sair com uma certa velocidade, a Terra } \\
\text { continua puxando ele para baixo. }\end{array}$ & ADC \\
\hline 177. Wag: Ele vai sair sem atingir os $11,6 \mathrm{~km} / \mathrm{s}$, não vai? & 177. AAQ \\
\hline $\begin{array}{l}\text { 178. P: Onde ele tem que estar com os } 11,6 \mathrm{~km} / \mathrm{s} \text { para sair da } \\
\text { Terra? No começo ou atinge no fim? }\end{array}$ & \\
\hline Jag: No fim, não é? & 179. AAE \\
\hline m momento de $\mathrm{s}$ & \\
\hline $\begin{array}{l}\text { dade ele sai com vários foguetes e depois } \\
\text { eparam com a (...). }\end{array}$ & $\begin{array}{l}\text { 181. AAE, } \\
\text { AAIns } \\
182 \text { FA }\end{array}$ \\
\hline $\begin{array}{l}\text { Hel: Eu acho que na verdade é o lançador, e depois lá em cima } \\
\text { se separam, a sonda espacial, o satélite. }\end{array}$ & $\begin{array}{l}\text { 183. AAE, } \\
\text { AAIns }\end{array}$ \\
\hline Wag: Mas daí depois que já saiu da atmosfera? & 184. AAQ \\
\hline $\begin{array}{l}\text { P: Pensem sobre esse assunto, a gente volta a discutir isso ai, é } \\
\text { bom assunto. O assunto é o seguinte: onde é que tem que estar } \\
\text { velocidade de } 11,6 \mathrm{~km} / \mathrm{s} \text {, na saída, ou no final? }\end{array}$ & \\
\hline $\begin{array}{l}\text { Mur: Ele sai devagar, vai acelera a velocidade, ele não sai em } \\
\text { osão, mas não chega a dar essa velocidade, depois que ele } \\
\text { eça ganhar velocidade. } \\
\text { Hel: Começa do zero. }\end{array}$ & $\begin{array}{l}186,187,189 . \\
\text { AAE }\end{array}$ \\
\hline ag: Então, ele & 188. AAC \\
\hline $\begin{array}{l}\text { Ric: Por mais força que ele tenha, ele não vai sair do zero e ir } \\
11,6.10 \mathrm{~km} / \mathrm{h}, 100 \mathrm{~km} / \mathrm{h}, 200,1000 \text { e vai até essa velocidade aí. }\end{array}$ & AAQ \\
\hline $\begin{array}{l}\text { Wag: Então, mas tem que ver onde é esse começo aí, é } \\
\text { a? No começo, no meio? }\end{array}$ & 190. AAQ \\
\hline 191.Wag: A atmosfera tem quantos $\mathrm{km}$ ? & 191. AAQ \\
\hline $\begin{array}{l}\text { 192. P: A atmosfera é uma camada de ar de } 700 \mathrm{~km} \text {, mas a } \\
\text { gravidade não termina no final da atmosfera. } \\
\text { 193. P: Gente, depois a gente volta a discutir esse assunto, vamos }\end{array}$ & 19 \\
\hline
\end{tabular}

No início desse episódio (momento 154) o professor interrompeu a leitura com o objetivo de envolver os alunos com o tema em questão, determinando os conteúdos a serem considerados, por meio de um discurso autoritário, utilizando uma abordagem comunicativa interativa/de autoridade. Com isso, o mesmo usou uma argumentação retórica para contextualizar o assunto tratado no texto e, com isso, direcionar o fluxo de comunicação. Considera-se que, nesse momento (154), o professor poderia ter 
comentado que o valor de g é de aproximadamente igual a $10 \mathrm{~m} / \mathrm{s}^{2}$ se o corpo estiver próximo à superfície da Terra. Entretanto, se o mesmo estiver a uma altura considerável em relação à superfície, o valor de g é menor. A seguir, o professor optou por instigar os alunos a colocarem as suas opiniões.

Isso levou o aluno Oli a inserir um novo elemento à discussão (momentos 155 , 157 e 159), demonstrando, assim, ter relacionado os conhecimentos trabalhados no texto, acerca de peso e massa de um corpo, com a sua estrutura cognitiva, de maneira não arbitrária e substantiva (AUSUBEL, apud MOREIRA 1997), o que pode indicar uma aprendizagem significativa crítica por parte do mesmo. Esse aluno, por meio de uma ação argumentativa elaborativa, demonstrou a compreensão da diferença entre os referidos conceitos, embora tenha se utilizado de uma terminologia diferenciada em relação à tradicionalmente usada dentro da Física, uma vez que ao se referir à massa de um corpo, o mesmo utilizou o termo "peso estável".

Mediante a colocação de Oli, o professor, por meio de uma argumentação socrática de reespelhamento (momento 156), autorizou o argumento do aluno. Entretanto, julgou necessário, no momento 158, precisar a idéia do aluno, utilizando uma argumentação socrática de remodelamento, a fim de esclarecer o significado do termo "peso estável" usado pelo aluno, bem como buscou a lógica desse argumento, no momento 160 , por meio de uma fala avaliativa.

$\mathrm{Na}$ seqüência (momento 162), o professor buscou discernir o conceito de massa e peso, assumindo uma argumentação socrática de elucidação e, a seguir, colocou uma pergunta para levar os alunos a explicitarem as suas opiniões (argumentação dialógica de instigação).

Isso levou o aluno Hel (momento 163) a demonstrar a compreensão dos conceitos de massa e peso. A sua resposta indica que o mesmo reelaborou o seu conceito (ação argumentativa reelaborativa), uma vez que no capítulo anterior, ele havia demonstrado não discernir massa e peso de um corpo. Wag (momento 164) também demonstrou a compreensão dos referidos conceitos ao complementar a resposta de Hel, por meio de uma ação argumentativa concordante. Isso pode ser uma evidência de aprendizagem significativa crítica por parte desses alunos. Essas respostas levaram o professor a assumir uma argumentação socrática de remodelamento (momento 165), dando contornos mais precisos às idéias construídas pelos alunos. 
Wag (momentos 166, 168, 170) retomou o problema da velocidade de escape, por meio de uma ação argumentativa questionadora, elaborando uma pergunta relevante acerca desse assunto, o que denota uma aprendizagem significativa crítica por parte do mesmo. Em princípio (momento 167) o professor assumiu uma postura diretiva, por meio de uma argumentação socrática de elucidação, a fim de responder à pergunta do aluno. A seguir (momento 169) o mesmo procurou instigar os alunos a explicitarem as suas opiniões acerca do assunto (argumentação dialógica de instigação).

Mediante a hipótese colocada por Mur (momentos 171, 173), o professor, por meio de uma fala avaliativa (momento 172), buscou a lógica do argumento do aluno. A reação do professor, a partir da resposta do aluno, colocando a questão "A gravidade da atmosfera?" (momento 174) com uma entonação de voz como de quem não entendeu o que o aluno quis dizer, pode ter levado o referido aluno a perceber que o professor não concordou com a sua hipótese (argumentação socrática de reespelhamento), embora o mesmo não tenha se referido a mesma como "errada". A resposta do aluno (“Ahn”) pode sugerir que o mesmo percebeu que a sua hipótese não era adequada do ponto de vista científico.

O professor poderia ter explorado essa concepção espontânea do aluno a fim de reforçar o conceito de força de atração gravitacional. Entretanto, o mesmo, por meio de uma argumentação dialógica de contraposição (momento 176), destacou o ponto contraditório referente à argumentação de Mur.

A seguir, Wag elaborou uma questão relevante para ser discutida (momento 177), o que pode ser um indício de aprendizagem significativa crítica por parte do aluno. No entanto, o professor não esclareceu a dúvida de Wag de imediato, mas colocou uma nova pergunta, utilizando-se de uma argumentação dialógica de instigação (momento 178).

O silêncio demonstrado pelos alunos no momento 180 pode indicar reflexão por parte de alguns alunos, enquanto por parte de outros alunos pode indicar desconhecimento, ou mesmo desinteresse a respeito do assunto. As colocações de Wag, Hel, Mur e Ric (momentos 179, 181, 183, 184, 186, 187, 188, 189, 190, 191) denotam que os mesmos estavam refletindo sobre o problema enquanto permaneceram em silêncio.

Percebe-se ainda que, do momento 166 ao 192, houve uma interação social que resultou em uma negociação de significados entre os alunos e entre professor e 
alunos, envolvendo uma troca constante de questionamentos (MOREIRA, 2005). Essa seqüência pode evidenciar um contexto de aprendizagem significativa crítica por parte desses alunos.

Destaca-se ainda que, no momento 184, a pergunta colocada por Wag pode indicar que o mesmo apresentou a concepção de que a gravidade acaba com o fim da atmosfera, reiterando essa idéias no momento 191. O professor, percebendo a concepção inadequada de Wag (em termos científicos), utilizou uma argumentação dialógica de contraposição a fim de destacar esse ponto contraditório no argumento do aluno.

Com relação ao momento 193, o professor, em entrevista, admitiu que resolveu dar esse tempo para que ele próprio pudesse refletir sobre o assunto, ou seja, "onde o foguete tem que estar com 11,6 km/s para sair da Terra? No começo ou atinge no fim?" (momento 178). É interessante o professor ter colocado essa questão, pois a qual fim ele se referiu, uma vez que a gravidade vai diminuindo infinitamente? Essa colocação do professor pode ter levado o aluno Wag a associar o fim da gravidade com o fim da atmosfera.

\section{Análise e discussão dos resultados}

A partir do objetivo proposto no presente artigo, podemos dizer que a interação entre os alunos e o texto mediados pelo professor viabilizou a construção de um espaço dialógico que propiciou a ocorrência de contextos de aprendizagem significativa crítica relativa aos conhecimentos abordados.

Para tal, consideramos que a postura do professor propiciou essa ocorrência, uma vez que o mesmo assumiu, predominantemente, argumentações socráticas e dialógicas, no sentido de trabalhar os conceitos físicos emergentes das interações entre alunos/texto/professor, explorando as idéias dos alunos e trabalhando diferentes pontos de vista.

Essa postura aberta do professor refletiu na postura dos alunos que não se sentiram constrangidos em explicitarem os seus argumentos, contra-argumentos, ou mesmo em colocarem novos elementos a serem discutidos. Isso denota que o professor não assumiu um comportamento arbitrário e radical, qualquer que tenha sido o padrão discursivo utilizado pelo mesmo. Com isso, os alunos participaram ativamente da atividade, colocando as suas opiniões, sem medo de errar, bem como questionando as colocações dos colegas, do professor ou do texto. 
Observa-se ainda que, ocorreram momentos de interação entre os alunos e o texto, senão de forma direta, buscando esclarecimentos ou colocando questionamentos acerca dos conteúdos físicos abordados no mesmo, de forma indireta, a partir das colocações do professor, com o propósito de trabalhar alguns conteúdos físicos relevantes para o mesmo.

Em seus argumentos, os alunos demonstraram que estabeleceram relações entre as novas informações, presentes no texto, e os seus conhecimentos prévios de forma crítica e reflexiva. Isso sugere a ocorrência de aprendizagem significativa crítica por parte dos mesmos, mostrando interesse e motivação em participarem ativamente das discussões, com grande negociação de significados. Esses resultados mostraram-se consistentes com os princípios que fundamentam a ocorrência da referida aprendizagem, uma vez que a interação social entre os alunos e o professor, mediados pelo texto, a partir da negociação de significados por meio da troca constante de perguntas relevantes, viabilizou que os alunos demonstrassem vários momentos de aprendizagem significativa crítica, relacionando de forma não arbitrária e substantiva os novos conhecimentos com os seus conhecimentos prévios.

Os resultados indicam ainda que o texto Nosso Universo mostrou-se "potencialmente significativo" para os alunos, aguçando a curiosidade e o interesse dos mesmos, de modo que vários estudantes demonstraram relacionar os conteúdos abordados no mesmo com os conhecimentos presentes em sua estrutura cognitiva. Esse fator vinculado ao papel mediador do professor, provendo situações problemáticas de modo a estimular a relação dialógica, bem como o fato de os alunos estarem dispostos a aprender, participando ativamente das discussões, por meio de perguntas relevantes, elaborando argumentações, contra-argumentações, bem como inserindo novos elementos e problemas, que surgiam a partir de suas interpretações e atribuições de significados, resultou na facilitação da aprendizagem significativa crítica. 


\section{Referências bibliográficas}

ALMEIDA, M.J.P.M.; QUEIROZ, E.C.L. Divulgação científica e conhecimento escolar: um ensaio com alunos adultos. Caderno CEDES: ensino de ciência, leitura e literatura. Ano XVIII, n. 41, p.62-68, jul. 1997.

ASSIS, A. Leitura, argumentação e ensino de Física: análise da utilização de um texto paradidático em sala de aula, 2005. 286f. Tese (Doutorado em Educação para a Ciência, Área de Concentração: Ensino de Ciências) - Faculdade de Ciências da Universidade Estadual Paulista, Bauru, 2005.

BOULTER, C. J.; GILBERT, J. K. Argument and science education. In: COSTELLO, P.J.M. e MITCHELL, S. (edts). Competing and Consensual Voices: the theory and pratice of argument. Multilingual Matters LTD, 1995. Cap.6, p. 84 - 98.

BRASIL. Secretaria de Educação Média e Tecnológica. Parâmetros Curriculares Nacionais + Ensino Médio: Orientações Educacionais Complementares aos Parâmetros Curriculares Nacionais - ciências da natureza, matemática e suas tecnologias. Brasília: MEC; SEMTEC, 2002, 144 p.

BRASIL. Secretaria de Educação Média e Tecnológica. Parâmetros Curriculares Nacionais: Ensino Médio. Parte III - Ciências da Natureza, Matemática e suas Tecnologias, Brasília: MEC/SEMT, 2000.

COMPIANI, M. As Geociências no Ensino Fundamental: um estudo de caso sobre o tema "A formação do Universo". 1996. 216f. Tese (Doutorado em Educação - Área de Concentração: Metodologia do Ensino) - Faculdade de Educação da Universidade Estadual de Campinas, Campinas, 1996.

MONTEIRO, M. A. A. Interações dialógicas em aulas de ciências nas séries iniciais: um estudo do discurso do professor e as argumentações construídas pelos alunos. 2002. 204f. Dissertação (Mestrado em Educação para a Ciência - Área de Concentração: Ensino de Ciências) - Faculdade de Ciências da Universidade Estadual Paulista, Bauru, 2002.

MOREIRA, M. A. Aprendizagem significativa crítica = Aprendizage significativo critico. 47p. Texto em português e espanhol em direções opostas. CIP-Brasil, 2005.

MOREIRA, M.A. Linguagem e aprendizagem significativa. In: ENCONTRO INTERNACIONAL LINGUAGEM, CULTURA E COGNOÇÃO, II, 2003, Belo Horizonte:UFMG. Anais. CD-ROM.

MOREIRA, M. A. Aprendizagem significativa crítica. III Encontro Internacional sobre Aprendizagem Significativa, p. 33-35, set, 2000.

MOREIRA, M.A. A teoria da aprendizagem significativa de Ausubel. In: Ensino e aprendizagem: enfoques teóricos. São Paulo: Moraes. 1995, p.61-73.

MORTIMER, E.F.; SCOTT, P. Atividade discursiva nas salas de aula de ciências: uma ferramenta sociocultural para analisar e planejar o ensino. In: Investigações em ensino de ciências. n. 3, v. 7, p. 1-38, dez. 2002. Disponível em $<$ http://www.if.ufrgs.br/pulic/ensino/vol7/n3/v7_n3_a7.htm>. Acesso em 01 jan. 2004.

ORLANDI, E.P. A linguagem e seu funcionamento: as formas do discurso. $4^{\mathrm{a}}$ ed. Campinas: Pontes, 2001.

TEIXEIRA, O.P.B. (org). Nosso Universo, 2002. 126p. texto mimeog. 
Dinâmica discursiva e o ensino de Física: análise de um episódio de ensino envolvendo o uso de um texto alternativo

DATA RECEBIMENTO: 29/03/2007

DATA APROVAÇÃO: 03/07/2007 